\title{
David C. Lindberg, Ronald L. Numbers, éds., When Science and Christianity Meet
}

Chicago, The University of Chicago Press, 2003, XII+357 p.

\section{Patrick Harismendy}

\section{(2) OpenEdition}

\section{Journals}

Édition électronique

URL : http://journals.openedition.org/assr/3981

DOI : 10.4000/assr.3981

ISSN : $1777-5825$

Éditeur

Éditions de l'EHESS

\section{Édition imprimée}

Date de publication : 1 décembre 2006

Pagination : 115-283

ISBN : 2-7132-2124-2

ISSN : 0335-5985

Référence électronique

Patrick Harismendy, « David C. Lindberg, Ronald L. Numbers, éds., When Science and Christianity Meet ", Archives de sciences sociales des religions [En ligne], 136 | octobre - décembre 2006, document 136-67, mis en ligne le 13 février 2007, consulté le 21 septembre 2020. URL : http:// journals.openedition.org/assr/3981; DOI : https://doi.org/10.4000/assr.3981

Ce document a été généré automatiquement le 21 septembre 2020.

(C) Archives de sciences sociales des religions 


\section{David C. Lindberg, Ronald L. Numbers, éds., When Science and Christianity Meet}

Chicago, The University of Chicago Press, 2003, XII+357 p.

\section{Patrick Harismendy}

1 L'ouvrage se destine en principe au grand public « éclairé » et aux étudiants de premier cycle ce qui explique son caractère didactique (les notes sont reportées en fin de volume, mais sans rien y sacrifier). Les directeurs d'ouvrage, l'un comme l'autre historiens des sciences, ont en effet pris le parti de s'entourer d'une équipe de contributeurs pour présenter douze dossiers significatifs des rapports complexes entre christianisme et sciences - le but étant de montrer les systèmes d'intrication idéologiques ou culturels, par lesquels se lient les deux termes du propos. On part ainsi de la dynamique de restauration de la science chrétienne à travers la redécouverte du substratum antique (D.C. Lindberg mettant en regard l'analyse augustinienne et celle de Robert Bacon) pour terminer sur le constat d'une dichotomie actuelle, mais sans doute transitoire, entre Science et Religion, entre lois naturelles et convictions spirituelles (R.L. Numbers). Entre ces deux môles, le volume se veut relativiste. Rétif à toute téléologie, il entend vulgariser l'histoire des sciences, avec un souci de clarté que renforcent des plans d'articles très repérables et des illustrations (gravures et dessins surtout, quelques photos) vraiment conçues pour éclairer le texte. À ce titre, les contributions sont autant de "leçons» ou de case histories susceptibles d'être prolongées grâce à des bibliographies autonomes, certes brèves mais de la plus grande actualité. Le propos prend à bras le corps des dossiers connus et débattus, pour tenter d'en éclairer les enjeux propres. Ce qui ne manque pas de courage quand on sait le nombre infini d'interprétations possibles. Une attention particulière est accordée aux conditions de productions et de diffusion de la science - ce souci de contextualisation n'étant pas toujours respecté ailleurs. Ainsi, la juxtaposition des articles de W.B. Asworth Jr. et T.H. Broman permet de voir comment s'est déporté, notamment à 
travers l'émergence de la science comme production sociale, l'appréhension du réel, théorique chez Descartes, Gassendi, Newton, Hobbes, Boyle ; puis matérialiste chez Galilée ou Hume. Dans un très bel essai consacré à l'arche de Noé, Janet Browne montre que les débats sur la véracité du Déluge et de la conservation des espèces ne se sont pas réduits à des querelles de casuistique mais ont, bien au contraire, engendré un souci de l'inventaire, permis des calculs d'hydrauliques ou stimulé l'architecture navale. De même, si Mott T. Grenne aborde le dossier, très connu, de l'âge de la terre, du périodisme et du concordisme à travers les itinéraires de Buckland ou Lyell, il signale justement que la géologie est fille de la minéralogie et de l'exploitation minière, l'Angleterre du XIX ${ }^{\mathrm{e}}$ siècle se voyant dans le dessein de Dieu et étant donc peu encline à le contester. Des facteurs environnementaux similaires expliquent, selon G. Blair Nelson, le succès relatif des théories polygéniste et préadamite dans l'Amérique des tribus indiennes et de l'esclavage (Morton, Gliddon, Agassiz, contre Bachman) conduisant tout droit à la hiérarchisation ethnique, dominée par les seuls enfants (sic) du Créateur - ce qui permet, au passage, de conforter la chronologie biblique et de ne pas accorder le droit de vote aux Noirs après la guerre civile, malgré l'entrée en scène $\mathrm{du}$ développementalisme darwinien. David L. Livingstone combat justement les interprétations anachroniques qui associent ou opposent darwinisme et calvinisme, évolutionnisme et évangélisme, matérialisme et théisme (p. 202). Au terme d'une mise en perspective culturelle, il préfère insister sur l'autonomie des deux champs et le poids des facteurs psychologiques. Jon H. Roberts parvient globalement à la même conclusion en abordant les relations entre christianisme américain et psychanalyse qui le conduisent à nuancer l'opposition a priori entre les deux termes. Il suggère même que le débat sur la psychanalyse sans les Églises américaines leur a permis de rompre avec un certain infantilisme au profit d'un "réalisme chrétien». Dans l'aval de la controverse darwinienne, R.B. Mullin s'attache à la confrontation entre le physicien Tyndall et le high-churchman Mozley, apologue, contre la doxa calviniste, de la validité contemporaine des miracles et de l'efficience de la prière (jusqu'à son énergie, éventuellement mesurable) alors investie d'un pouvoir renouvelé par l'establishment. Enfin, Edward J. Larson adopte la même méthode pour présenter le procès Scope, non sous l'angle des débats scientifiques, mais à l'échelle dramaturgique du Tennessee rural des années 1920, dans la salle d'audience et sur fond de scène médiatique animée par la presse new-yorkaise, puis nationale. Malgré la richesse du volume, certains articles demeurent cependant factualistes ou trop biographiques - le principal reproche étant, en fait, de vouloir atténuer les conflits passés entre scientifiques et autorités ecclésiastiques. Les libres-penseurs ou anticléricaux semblent alors désignés pour avoir entretenu, à tort, un climat de suspicion. En témoigne ici l'« affaire » Galilée lue comme un drame psychologique, politique et géostratégique, ce qui n'est pas inintéressant mais peut prêter à confusion. Au bout du compte, l'austérité de la présentation comme la petite taille des caractères destinent moins l'ouvrage au public visé, qu'aux étudiants avancés ; il rendra cependant les plus grands services. 